\title{
A MULTIMODALIDADE DO VIDEOCLIPE MUSICAL: ASPECTOS METODOLÓGICOS PARA O ENSINO DE LÍNGUA INGLESA
}

\author{
ANA PAULA DOMINGOS BALADELI (UFG) ${ }^{1}$ \\ http://orcid.org/0000-0001-8508-0350
}

\begin{abstract}
RESUMO: A Teoria dos Multiletramentos enfatiza que a sofisticação das mídias potencializa a variedade de recursos audiovisuais como discurso próprio da contemporaneidade. Em termos educacionais, a multimodalidade amplia o acesso do aluno a significados e, destaca a hibridização das linguagens na composição de textos. O objetivo deste artigo é apresentar os resultados de um projeto de extensão sobre os multiletramentos, com ênfase no uso pedagógico do videoclipe musical. Os resultados do projeto, realizado em uma universidade pública no Brasil indicaram; a necessidade de o professor definir critérios para a seleção de videoclipe musical, a definição de objetivos para o uso do videoclipe, a articulação do videoclipe a conteúdos para aprendizagem em Língua Inglesa. Em linhas gerais, concluímos a relevância do papel das narrativas audiovisuais na formação de leitores críticos e, sobretudo, na aprendizagem de Língua Inglesa.
\end{abstract}

PALAVRAS-CHAVE: Multimodalidade. Videoclipe musical. Língua Inglesa.

ABSTRACT: The Multiliteracies theory emphasizes that the sophistication of media enhances the audiovisual resources variety as typical contemporary discourse. In pedagogical terms, multimodality extends the student access to meanings and highlights the hybridizations of language in text composition. The aim of this paper is to present the outcomes of an extension project about multiliteracies with emphasis on pedagogical use of musical video clip. The outcomes of the project conducted in a public university of Brazil indicated; the need of teachers defining criteria for musical video clip selection, the definition of objectives for the use of video clip, the link between the video clip and the English language content. In general, we conclude the relevance of audiovisual narratives in critical reader's education and, mainly in English language learning.

KEYWORDS: Multimodality. Video music. English language.

\section{INTRODUÇÃO}

A Teoria dos Multiletramentos tem sido amplamente difundida no cenário científico, em decorrência do seminário realizado no final da década de 1990. O grupo que liderou as discussões do evento ficou conhecido como Grupo de Nova Londres (GNL), responsável pela definição de Multiletramentos e Letramentos Múltiplos e seus desdobramentos na educação. $\mathrm{Na}$ ocasião, defenderam a emergência no delineamento de uma concepção de educação apropriada à nova lógica sociocultural, composta pela hibridização de linguagens, novos arranjos discursivos, expansão da multiculturalidade e diversidade linguística (NEW LONDON GROUP, 1996).

Fundamentados na emergência educacional contemporânea presente no mundo do trabalho e no avanço de tecnologias, os idealizadores do manifesto justificaram que se fazia necessária a revisão da concepção tradicional de letramento. $O$ argumento central fundamentou-se em pesquisas básicas e aplicadas que, evidenciaram que os letramentos variavam em tipos e níveis (STREET, 2012; COPE e KALANTZIS, 2015). Por conseguinte, o acesso e o papel da escrita nas práticas sociais representavam mais que mera habilidade

\footnotetext{
${ }^{1}$ Doutora em Letras. Professora da Universidade Federal de Goiás. E-mail: annapdomingos@yahoo.com.br Revista Trama | Volume 16 | Número 39 | Ano 2020 | pp. 81-90 | e-ISSN 1981-4674
} 


\section{$=$ TRAMA $=$}

cognitiva, mas um bem sociocultural significativo em valores, crenças e representações de identidades.

Dentre as contribuições do GNL, destacamos primeiro o processo de globalização e seus efeitos na educação, sobretudo nos estudos na área de ensino e aprendizagem de língua estrangeira. Em segundo lugar, a sofisticação das tecnologias e seus desdobramentos nos novos modos de representação da linguagem que se materializam em gêneros híbridos e, em terceiro, a diversidade cultural. Tais fatores trouxeram à tona revisões conceituais sobre letramentos e o papel da escrita no cenário contemporâneo.

Lidar com as diferenças linguísticas e culturais agora se tornou central nas pragmáticas de nossas vidas profissionais, cívicas e particulares. Agora, a efetiva cidadania e o trabalho produtivo exigem que interajamos efetivamente usando vários idiomas, vários Ingleses e padrões de comunicação que cruzam com mais frequência as fronteiras culturais, comunitárias e nacionais (NEW LONDON GROUP, 1996, p. 64).

No escopo das pesquisas nos Novos Estudos do Letramento, referencial que abarca pesquisadores de diferentes áreas do conhecimento, os multiletramentos e a multimodalidade tem ganhado visibilidade no cenário acadêmico, em especial na formação de professores. Dessa forma, o campo dos letramentos tornou-se espaço profícuo para a realização de pesquisas nas mais variadas áreas de estudo, mas, sobretudo em Linguística Aplicada.

Conforme New London Group (1996); Baguley, Pullen e Short (2010); Street, (2012); Cope e Kalantzis (2015), as pesquisas que tem como objeto a forma particular como os diferentes grupos sociais se apropriam da escrita, da leitura e como a ressignificam em seu contexto sociocultural estão relacionadas aos letramentos múltiplos. Os pesquisadores que, por sua vez, analisam a multimodalidade discursiva, ou seja, a hibridização das linguagens (letramento visual, letramento científico, letramento digital, letramento em saúde, letramento literário), estão alinhados à vertente dos estudos dos multiletramentos. Todavia, isso não significa que ambas as vertentes sejam dicotômicas, pelo contrário, é possível encontrar estudos que consideram a relevância tanto da multimodalidade quanto das práticas sociais situadas no processo de produção de significados.

Para Street (2012), os letramentos mobilizam valores e crenças dos grupos sociais, dado que impacta o processo de leitura e a forma como ressignificam o mundo por meio da escrita. A premissa levantada pelo pesquisador era a de que, as transformações tecnológicas associadas à diversidade cultural, propagadas em textos em diferentes modos de representação, exigiriam novas habilidades de leitura, dando origem à Teoria dos Multiletramentos.

Disso decorre o texto multimodal, que incorpora a multissemiose como característica constitutiva de gêneros textuais que circulam em diferentes suportes, inclusive interativos. Além disso, a identificação da função enunciativa de textos multimodais exige do interlocutor (leitor), engajamento para a mobilização de conhecimento prévio e leitura dos efeitos da multissemiose nos significados. Conforme Rojo e Moura (2012); Barbosa e Araújo (2016); Warner e Dupuy (2017); Baladeli (2019), a multimodalidade efetiva, de forma orgânica, imagens, signos, áudio, cores, contornos e nuances que também precisam ser interpretados como parte do discurso veiculado. Por essa razão, acreditamos que a Teoria dos Multiletramentos representa uma alternativa formativa para o ensino de línguas, visto que se coaduna ao contexto mediado por suportes e mídias interativas.

No cenário do ensino e aprendizagem de Língua Inglesa, podemos destacar as seguintes contribuições da Teoria dos Multiletramentos, (i) ampliação da concepção de letramento, (ii) 


\section{$=$ TRAMA $=$}

compreensão do papel dos diferentes modos de representação da linguagem na composição textual e (iii) reconhecimento da diversidade linguística e cultural.

O objetivo deste artigo é apresentar os resultados de um projeto de extensão sobre os multiletramentos, com ênfase no uso pedagógico do videoclipe musical no ensino de Língua Inglesa. Para tanto, na primeira seção - Multimodalidade em sala de aula: conceitos caracterizamos a multimodalidade e seu papel nos textos audiovisuais, na segunda - $A$ multimodalidade no videoclipe musical: alguns encaminhamentos - apresentamos as ações de um projeto de extensão sobre o tema, e nas Considerações finais, problematizamos os desafios inerentes ao uso pedagógico do videoclipe musical no ensino de Língua Inglesa.

\section{MULTIMODALIDADE EM SALA DE AULA: CONCEITOS}

Conforme apresentamos na introdução, na gênese das reivindicações do GNL estava a emergência de uma pedagogia voltada para a realidade do século XXI, caracterizada pela diversidade cultural e avanço de tecnologias, pois acreditavam na interferência destes fatores na forma como os sujeitos e grupos sociais acessam, organizam e ressignificam a escrita. Portanto, um currículo transversal, que possibilite a interculturalidade como elemento aglutinador, se tornaria o mais apropriado para consolidar a almejada formação de sujeitos para os multiletramentos.

Para Berk (2009); Baguley, Pullen e Short (2010); Warner e Dupuy (2017) a formação para os multiletramentos permite o desenvolvimento de estratégias para a multimodalidade como parte constituinte do discurso, o reconhecimento da dimensão transcultural e crítica do discurso verbo-visual. Para os propósitos deste artigo, nosso foco é o ensino de Língua Inglesa na Educação Básica e as possíveis contribuições da Teoria dos Multiletramentos na educação.

No caso do projeto em questão, o texto multimodal - videoclipe musical - é composto por imagens em movimento, cenário, narrativa, áudio e letra, representando, portanto, um potencial objeto para o ensino de Língua Inglesa. Por requerer do interlocutor (leitor) maior comprometimento durante a atividade de leitura, exige um conjunto de competências que favoreçam tanto a leitura crítica quanto a produção de significados a partir da multissemiose que o compõe. Nesses termos, a Teoria dos Multiletramentos pode representar uma alternativa para a prática pedagógica do professor, visto que articula as práticas de letramentos dos alunos com o letramento escolar.

Segundo a Base Nacional Comum Curricular - BNCC (BRASIL, 2018), documento recente que norteia a educação básica no país, a aprendizagem de uma língua estrangeira representa uma oportunidade enriquecedora de repertório linguístico, discursivo e cultural do aluno. De modo que, na contemporaneidade, o ensino de Língua Inglesa deve ser desterritorializado e capaz de subverter percepções hegemônicas de cultura.

Para o trabalho pedagógico, cabe ressaltar que diferentes recursos midiáticos verbo-visuais (cinema, internet, televisão, entre outros) constituem insumos autênticos e significados, imprescindíveis para a instauração de práticas de uso/interação oral em sala de aula e de exploração de campos em que tais práticas possam ser trabalhadas (BRASIL, 2018, p. 243).

O videoclipe musical, gênero de fácil acesso em plataformas de vídeo e mídias sociais, pode ser inserido na Educação Básica, visto que pode despertar maior interesse dos alunos pela aprendizagem de Língua Inglesa à medida que observavam proximidade entre seus letramentos e os letramentos escolares. Em vista disso, conhecer as contribuições da Teoria dos Multiletramentos e adaptar o ensino de Língua Inglesa aos letramentos emergentes torna- 


\section{$=$ TRAMA $=$}

se um imperativo para tirar proveito de tais recursos e formar leitores críticos para o texto multimodal e recursos audiovisuais.

$\mathrm{Na}$ sala de aula, o aluno tem pela frente o desafio de produzir significados considerando que a imagem em movimento também precisa ser interpretada e que, na maioria das vezes não representa a mera descrição ou dramatização da letra da canção. Para tanto, precisa identificar aspectos no videoclipe que ampliam os significados identificáveis na letra e estabelecer relações do tema com outras áreas do conhecimento. Os códigos visuais e sonoros e demais efeitos desencadeados na experiência do interlocutor com o audiovisual são relevantes para compreender as formas particulares com que os alunos processam os conteúdos (BULL e ANSTEY, 2019).

Em outras palavras, o uso de videoclipe musical em sala de aula transcende os conteúdos da disciplina de Língua Inglesa, visto que se inter-relaciona a outros conteúdos escolares. Ao propor a leitura de imagens e a discussão a partir da multimodalidade de um videoclipe musical, o aluno tem a oportunidade de realizar leituras por diferentes perspectivas. Já o professor, ao inserir o gênero videoclipe musical em sala de aula, favorece a abordagem transdisciplinar, dado que amplia os horizontes dos alunos e enriquece o repertório que constroem na/sobre a Língua Inglesa.

A transdisciplinaridade, como o prefixo 'trans' indica, diz respeito àquilo que está ao mesmo tempo entre as disciplinas, através das diferentes disciplinas e além de qualquer disciplina. Seu objetivo é a compreensão do mundo presente, para o qual um dos imperativos é a unidade do conhecimento (NICOLESCU, 2000, p. 11).

Considerando o potencial da transdisciplinaridade na educação, o videoclipe seria o fio condutor de aprendizagem para além dos limites da disciplina de Língua Inglesa, e por meio dele, o aluno poderia mobilizar conhecimentos de várias naturezas praticando outros tipos e níveis de letramento. O desafio posto ao ensino de línguas é reconhecer que, a imersão nas multissemioses do texto verbo-visual demanda um conjunto de estratégias que subsidiem o reconhecimento do projeto de dizer do audiovisual (SERAFINI, 2011; BOCHE, 2014; BALADELI, 2019).

O uso de textos multimodais em sala de aula poderá ainda ampliar o debate sobre o papel das multissemioses na construção de sentidos, para além de sua função meramente ilustrativa, e em seu lugar, representar materialidades discursivas reveladores de ideologias e intencionalidades (BALADELI, 2019, p. 25).

A formação para os multiletramentos implica em considerar a multimodalidade como constitutiva dos textos, bem como o seu potencial para a aprendizagem de diferentes conteúdos. Para este propósito, faz-se necessário considerar a influência dos suportes e a sofisticação das tecnologias digitais influencia na configuração dos textos na atualidade. $O$ texto, antes compreendido como objeto essencialmente linguístico, completo e estável na cultura grafocêntrica, passa a ser multimodal, editável e volátil (KRESS e VAN LEEUWEEN, 2006; SERAFINI, 2010, 2011; COPE e KALANTZIS, 2015). Com as múltiplas conexões e a relação de interdependência presente em textos verbo-visuais, o processo de leitura é complexificado exigindo novas abordagens para a formação do leitor. O professor precisa mediar esta prática, destacando para o aluno que o audiovisual apresenta indícios de significados e, que a leitura da hibridização dos modos de representação da linguagem exige confronto e estabelecimento de comparações, ou seja, problematização. 


\section{$=$ TRAMA $=$}

\section{A MULTIMODALIDADE NO VIDEOCLIPE MUSICAL: ALGUNS ENCAMINHAMENTOS}

O videoclipe musical tem a função de divulgar a canção/banda, apresenta algumas vantagens como recurso pedagógico, quais sejam; ser relativamente curto e pode ser facilmente acessado pelo aluno em plataformas de vídeos e em serviços de streaming. Todavia, embora vantajoso, o videoclipe musical precisa passar por criteriosa seleção, pois o professor precisa planejar as atividades considerando o potencial de aprendizagem do audiovisual (BERK, 2014; McCLAIN, 2016).

Segundo destacam Bull e Anstey (2019) os diferentes tipos de vídeos desencadeiam diferentes sentimentos e reações, podendo ser raiva, empatia, indignação, riso, sono, indiferença, motivação, relaxamento, calma, contentamento entre outros. O videoclipe musical em sala de aula pode despertar variadas reações, motivações e frustrações nos alunos, por essa razão, a mediação do professor é relevante.

O relato a seguir apresenta os resultados do projeto de extensão - Laboratório dos multiletramentos: explorando o videoclipe musical no ensino de línguas, realizado em uma universidade pública do Centro-Oeste do país. O projeto teve o objetivo de promover a formação para os multiletramentos a partir da elaboração de atividades para o ensino de Língua Inglesa com o uso de videoclipe musical.

A opção pelo gênero videoclipe musical se deu em razão de este ser acessível aos alunos. Ao longo dos encontros do projeto, realizado entre abril a novembro de 2019, os 5 participantes (4 acadêmicos de Letras Inglês e 1 professora da Educação Básica) participaram de atividades de leitura, de debate e de elaboração de atividades para o ensino de Língua Inglesa a partir de videoclipe musical em Língua Inglesa. As metodologias adotadas em cada encontro variaram em razão das características dos vídeos exibidos, do tema da música e dos eixos a serem explorados.

$\mathrm{Na}$ perspectiva de Marchetti e Cullen (2016), se comparado a outros recursos, o videoclipe musical apresenta algumas vantagens, quais sejam, desperta o interesse dos alunos pelo conteúdo, estimula a criatividade nas interpretações do discurso imagético, dinamiza a aula, fornece possibilidades de participação e engajamento colaborativo, apresenta diversidade linguística, tem uma linguagem que já faz parte das práticas de letramento dos alunos. Além disso, o ritmo da canção e o design (estética) do vídeo podem favorecer aos alunos com estilo de aprendizagem sinestésico, ou seja, que necessitam de estímulos sensoriais, em estabelecer relações com o conteúdo do vídeo.

A importância da escolha do material adequado é do professor, mas pode facilmente ser estendida para os alunos, que podem participar escolhendo materiais adequados com a orientação do professor. Interesse e propósito são ingredientes essenciais e necessários que devem encaixar no currículo e nos requisites institucionais bem como nos objetivos imediatos e de longo prazo (MARCHETTI e CULLEN, 2016, p. 43).2

\footnotetext{
${ }^{2}$ Minha tradução para "The importance of the choice of suitable input material ultimately lies with the teacher but can easily be extended to students, who can participate in choosing suitable materials with the teacher's guidance. Interest and purpose are essential ingredients and necessarily ought to fit in with curriculum and institutional requirements as well as immediate and long-term objectives (MARCHETTI and CULLEN, 2016, p. 43).
} 


\section{$=$ TRAMA $=$}

Segundo a BNCC (BRASIL, 2018) o eixo da leitura deve favorecer o contato do aluno com a diversidade de textos e de abordagens, que explorem o conhecimento prévio e possibilitem a correlação dos conteúdos com sua prática social. Assim, foram destacadas as atividades de pré-leitura com base no título do videoclipe/canção, levantamento de hipóteses de leitura a partir da exibição de fotogramas selecionados do videoclipe, elaboração colaborativa de mapas mentais a partir do vocabulário específico da letra, identificação do conhecimento prévio dos alunos sobre a banda/cantor e o levantamento das expectativas em relação ao conteúdo do vídeo.

Como ponto de partida para a compreensão das multissemioses - linguagens que compõem o gênero videoclipe musical - algumas estratégias foram adotadas para que os participantes considerassem os procedimentos metodológicos para inserção do videoclipe no planejamento de uma aula de Língua Inglesa. A discussão considerou ainda, o potencial da proposta para a formação para os multiletramentos em que figurou a problematização sobre o uso pedagógico do videoclipe musical no ensino de Língua Inglesa. Os encontros oportunizaram inicialmente aos participantes a experiência de apreciação estética com o videoclipe musical, para isso, o processo de pesquisa e seleção foi motivado por interesse pessoal, gosto musical e atratividade do vídeo. Num segundo momento, porém, a recepção do videoclipe passou a ser motivada pela intencionalidade pedagógica e, portanto, aspectos relacionados às aprendizagens foram evidenciados.

Para Barbosa e Araújo (2014) o letramento visual possibilitaria ao aluno desenvolver competências para reconhecer que a imagem está diretamente relacionada ao processo de produção de sentido, sendo a multimodalidade relevante na formação do leitor contemporâneo que interage, publica e compartilha textos multimodais em suas interações mediadas por tecnologia.

[...] a imagem, que por muito tempo vinha sendo relegada ao papel de suporte ao texto escrito, embora sempre tenha estado presente em toda forma de comunicação, reassume uma importância nos mais variados contextos da sociedade contemporânea pelo impacto e influência que exerce sobre as pessoas como também pelo significado que veiculam (BARBOSA e ARAÚJO, 2014, p. 19).

A metodologia incluiu a realização de 12 encontros no total, com duração de 3 horas cada, em que se exibiu um videoclipe musical e se propôs um conjunto de atividades de Língua Inglesa considerando sua usabilidade no contexto da Educação Básica. Os videoclipes foram selecionados pelos participantes que, também desenvolveram atividades de pré-leitura, leitura e pós-leitura, a depender do tema do vídeo e dos eixos selecionados na proposta (oralidade, leitura, escrita, análise linguística, compreensão auditiva e competência intercultural).

O projeto evidenciou a viabilidade do uso do videoclipe musical como parte constituinte dos conteúdos estabelecidos no currículo, mas também ilustrou a relevância da prática de pesquisa, a delimitação de critérios, o estabelecimento de objetivos, o reconhecimento das contribuições do videoclipe no desenvolvimento dos eixos e o conhecimento de abordagens para a mediação da aula com o videoclipe musical. Durante os encontros houve a problematização sobre a abordagem mais adequada a cada videoclipe, bem como os impasses que poderiam dificultar a atuação do professor na escola para o uso do videoclipe musical em uma aula com duração de 50 minutos.

No que se referem às atividades, estas também variaram em razão do tema de cada videoclipe. Na sequência, apresentamos os fotogramas selecionados (fig. 01 e 02) do videoclipe intitulado October \& April da banda finlandesa Rasmus feat. Anette Olzon. As atividades iniciaram com o levantamento de hipótese sobre o título, sendo seguida pela exibição do vídeo 


\section{$=$ TRAMA $=$}

sem o áudio, dado que possibilitou que os participantes realizassem a leitura a partir das imagens, associando o título às suas predições de leitura.
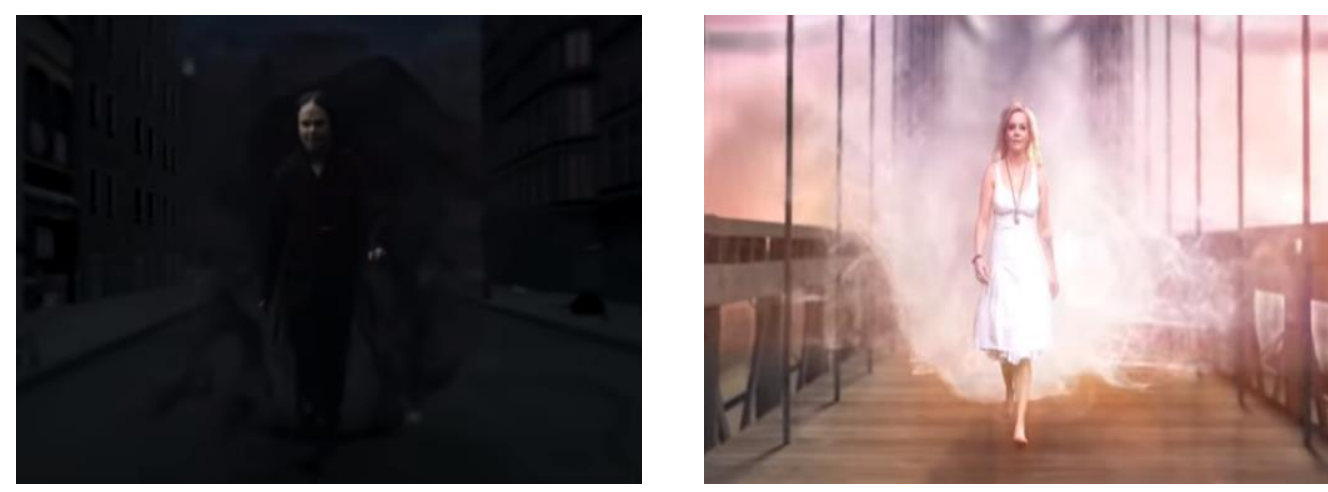

Fig 01 e Fig 02: October \& April, Rasmus e Annete Olson (Playground Music, 2009)

As atividades de pré-leitura para este videoclipe incluíram a exibição de cenas selecionadas e capturadas em fotogramas, a fim de que os participantes levantassem hipóteses sobre os significados do título e a caracterização das personagens. Após esta atividade, o videoclipe foi exibido na íntegra para que houvesse a confirmação ou não das hipóteses levantadas.

Na tentativa de superar a prática tradicional de uso da letra da canção em sala de aula, com base no preenchimento de palavras faltantes nos versos, somente com a $2^{a}$ exibição do videoclipe foi entregue aos participantes a letra da canção. Os participantes relacionaram o título com as diferenças entre as estações do ano e uma relação amorosa, isso porque, a letra apresenta vários jogos de opostos como light/dark, hate/love, também adjetivos que descrevem as estações do ano do hemisfério norte durante os meses de outubro e abril, outono e primavera respectivamente, como forma de descrever o relacionamento amoroso.

Para as atividades de vocabulário foi realizado o levanto do conhecimento prévio dos participantes sobre as especificidades das estações do ano no hemisfério norte, já que a falta dele poderia dificultar a identificação das analogias presentes no videoclipe entre as estações do ano e a descrição do relacionamento amoroso. Após a exibição do videoclipe na íntegra, em Língua Inglesa, os participantes socializaram suas leituras sobre a narrativa audiovisual, acompanharam o vídeo com a letra da canção, realizaram em duplas as atividades de análise linguística e identificaram a relação das cores usadas na narrativa com o tema do vídeo.

Ao assistir a um videoclipe musical, o aluno tem o desafio de identificar a função dos elementos constitutivos do vídeo em si, relacioná-lo ao gênero canção e interpretar a letra da canção. Essas ações requerem o planejamento por parte do professor que, ao optar por explorar o videoclipe como objetivo para o ensino de Língua Inglesa deverá considerar; o tema da canção, a qualidade e duração do videoclipe, a adequação do tema à idade dos alunos, os conteúdos ensináveis a partir do videoclipe e da canção, bem como os eixos a serem desenvolvidos em sala.

Outro exemplo de fotogramas usados no projeto foi selecionado do videoclipe Cape of our hero da banda Dinamarquesa Volbeat. O encontro foi iniciado com a projeção do título do videoclipe com o auxílio do PowerPoint e, perguntamos aos participantes sobre o que seria o vídeo. Após algumas respostas, centralizado na lousa, apresentamos a palavra HERO. Inicialmente, cada participante escreveu uma palavra em Língua Inglesa relacionada ao termo, atividade esta que foi se complexificando à medida que novas palavras foram relacionadas às palavras na lousa. 


\section{$=\mathrm{T} R A M A=$}

Além do mapa mental a partir da palavra-chave HERO, oralmente, cada participante apresentou sua definição de herói e descreveu algumas características do herói.

Esta primeira atividade possibilitou o levantamento de vocabulário em Língua Inglesa, a socialização da definição individual de herói e, também funcionou como pré-leitura, já que a partir da palavra-chave os participantes mobilizaram seus conhecimentos prévios sobre o título do videoclipe. Na sequência foram projetados dez fotogramas, conforme exemplo (fig. 03 e 04), a partir dos quais tiveram de relacionar ou descartar as palavras do mapa mental.

A primeira abordagem para o fotograma foi descrevê-lo em inglês. Na segunda, tiveram de identificar os indícios de significado nos fotogramas, relacioná-los ao que esperavam encontrar no videoclipe intitulado Cape of our hero e, se identificavam proximidade com a definição individual de herói.
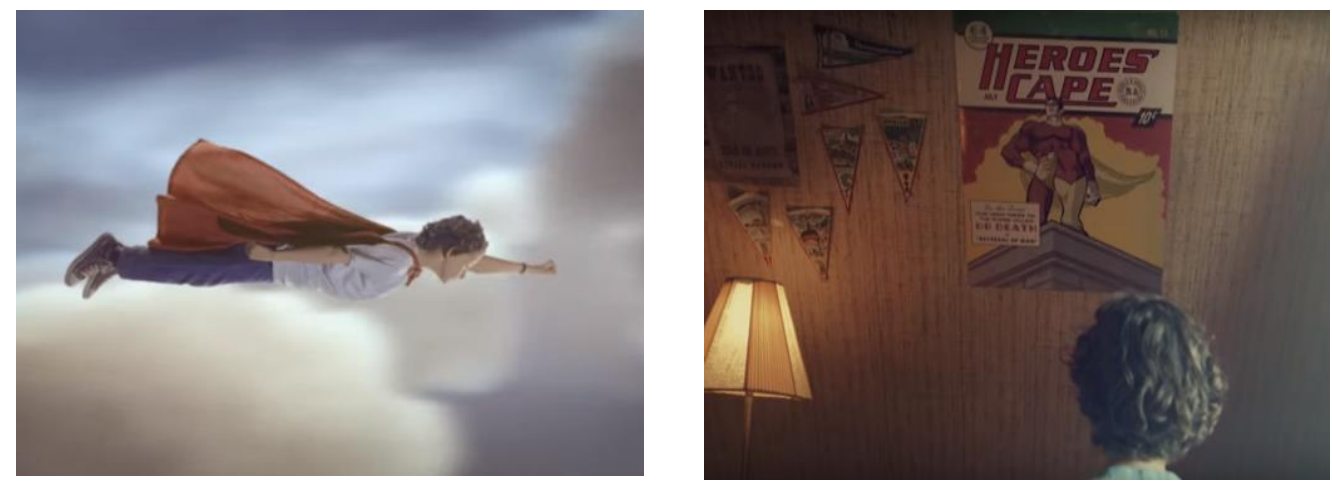

Fig 03 e Fig 04: Cape of our hero, Volbeat (Universal Music, 2013)

Nessa dinâmica, cada detalhe foi relevante para a atividade de leitura de imagem, por isso em vez de iniciarmos o encontro com a exibição do videoclipe na íntegra, antes, mobilizamos o vocabulário e hipóteses de leitura. As atividades na sequência foram a exibição do videoclipe na íntegra, a retomada da definição de herói produzida pelos participantes, a confirmação ou não das hipóteses de leitura sobre o tema do videoclipe, a exibição do videoclipe com pausas em cenas que os participantes destacaram como relevantes para a compreensão da narrativa, a leitura da letra da canção e o debate sobre a narrativa do videoclipe.

Além disso, foi entregue aos participantes uma sequência didática impressa com as atividades em Língua Inglesa e Língua Portuguesa. Nela continha, atividades de vocabulário (word search), de escrita (respostas discursivas interpretativas sobre o tema do videoclipe) e análise linguística (phrasal verbs, verb tense, cognates, antonym, synonym, rhymes, plural), este eixo para ser elaborado em pares. Ao final de cada encontro houve a socialização das impressões dos participantes sobre a proposta e sua viabilidade no contexto desta aula de Língua Inglesa na Educação Básica.

Nesse processo de reflexão coletiva, foram considerados aspectos como tempo e natureza de cada atividade, recursos materiais necessários, mediação do professor, a adequação do videoclipe musical ao público da Educação Básica, a intercalação entre atividades em Língua Inglesa e Língua Portuguesa, bem como o levantamento de pontos fracos das atividades. Os encontros oportunizaram a elaboração de critérios para a seleção de videoclipe musical/canção como objeto de ensino e, a problematização do uso do videoclipe musical como texto multimodal e não mero adereço audiovisual em sala de aula. 


\section{$=$ TRAMA $=$}

O uso de textos multimodais em sala de aula amplia as oportunidades de desenvolvimento dos eixos, oralidade, leitura, escrita, compreensão auditiva e competência intercultural, desde que haja coerência nas escolhas metodológicas feitas pelo professor, dado que, indubitavelmente requer formação e subsídio teórico.

Ao final do projeto de extensão concluímos que o uso pedagógico do videoclipe musical requer algumas estratégias, estas que podem auxiliar o professor a explorar o audiovisual como texto. Para este propósito, em termos metodológicos, destacamos; realização de mapa mental com o título da música, exibição sem áudio, com áudio e acompanhamento da letra, com áudio sem acompanhamento da letra, exibição na íntegra, exibição com pausas dialogadas em cenaschave selecionadas previamente pelo professor, exibição com pausas em cenas-chave identificadas como relevantes pelos participantes e apresentação de fotogramas selecionados do videoclipe, exibição na íntegra com áudio e acompanhamento da letra. Ademais, o mesmo videoclipe pode ser usado em diferentes séries, adaptando-se as atividades conforme os eixos a serem explorados e os conteúdos em Língua Inglesa selecionados.

\section{CONSIDERAÇÕES FINAIS}

A realização de um projeto de extensão sobre o uso pedagógico do videoclipe musical no ensino de Língua Inglesa evidenciou que, o potencial formativo do audiovisual depende de planejamento, de metodologia e de mediação apropriados. O projeto evidenciou também que o processo de seleção dos videoclipes demanda; critérios, articulação entre o objetivo da aula e os conteúdos ensináveis em Língua Inglesa, para que não se torne uma atividade fragmentada de interpretação de imagens e de narrativa audiovisual.

Acreditamos que um conjunto de metodologias e estratégias precisa acompanhar a proposta da aula a fim de que o videoclipe seja o texto principal a ser lido, a partir do qual se desenvolve um conjunto de atividades que, possivelmente, extrapolarão o limite de 1 aula de 50 minutos. Uma aula a partir de um videoclipe musical terá um tema, um conjunto de vocabulário e uma estética, que juntos, potencializarão a experiência do aluno com a Língua Inglesa. Um dos exemplos é o tema da canção a partir do qual o vocabulário será explorado nas atividades de pré-leitura, nas atividades dos eixos de oralidade, escrita e análise linguística. Além disso, há o design (estética) do videoclipe que pode ser ou não atrativo para o aluno, o que demanda mediação do professor para o destaque de detalhes da narrativa audiovisual e vantagem de ler para além dos indícios projetados na tela.

Considerando a necessidade de oportunizar aos participantes a reflexão crítica acerca da Teoria dos Multiletramentos, o projeto caracterizado como teórico-prático fomentou o planejamento de sequências didáticas para o ensino de Língua Inglesa tendo como recurso o videoclipe musical. Além disso, evidenciou a viabilidade no uso de videoclipe musical em sala de aula, primeiro por ser curto e poder ser exibido várias vezes durante a aula e, segundo, porque por meio dele é possível elaborar um conjunto de atividades transdisciplinares para ser realizadas ao longo de várias aulas.

Em linhas gerais, formar para os multiletramentos requer explorar criticamente o audiovisual, para que o aluno experencie o videoclipe musical, gênero em destaque neste artigo, de forma mediada e problematizadora, para além da dimensão de entretenimento. Ademais, formar para os multiletramentos contribui para a articulação entre os letramentos escolares e os letramentos praticados pelos alunos em suas práticas sociais que, possivelmente envolve interação mediada por tecnologia, produção e compartilhamento de textos multimodais. 


\section{$=\mathrm{T} R A M A=$}

\section{REFERÊNCIAS}

BAGULEY, Margaret; PULLEN, Darren L.; SHORT, Megan. Multiliteracies and the new world order. In: PULLEN, D.L.; COLE, D.R. Multiliteracies and technology enhanced education: social practice and the global classroom. Hershey: IGI Global, 2010. p. 01-17.

BALADELI, Ana P.D. Cibercultura e ensino de línguas: um olhar sobre a Teoria dos Multiletramentos. In: COSTA, N. V. S. (org.). A Língua Inglesa e seus desdobramentos na ciência. Bonecker, 2019. p. 11-28. BARBOSA, Vânia S.; ARAÚJO, Antonia D. Multimodalidade e letramento visual: um estudo piloto de atividades de leitura disponíveis em sítio eletrônico. Revista da ANPOLL, Florianópolis, n.37, jul./dez.2014, p.17-36. Disponível em: < https://revistadaanpoll.emnuvens.com.br/revista/article/view/824> acesso em 04 dez. 2019.

BERK, Ronald A. Multimedia teaching with video clips: TV, Movies, YouTube, and motive in the college classroom. International Journal of Technology in Teaching and Learning, v. 5, n.1, 2009, p. 1-21.

BOCHE, Benjamin. Multiliteracies in the classroom: emerging conceptions of first-year teachers. Journal of Language and Literacy Education, v.10, n.1, 2014.

BRASIL. Base Nacional Comum Curricular: Ensino Médio. Brasília: MEC/Secretaria de Educação Básica, 2018.

BULL, Geoff; ANSTEY, Michele. Elaborating multiliteracies through multimodal texts. London, New York: Routledge, 2019.

COPE, Bill; KALANTZIS, Mary. A pedagogy of multiliteracies, learning by design. New York. Palgrave Macmilan, 2015.

KRESS, Gunther; VAN LEEUWEN, Theo. Reading images. $2^{\text {nd }}$. London: Routledge, 2006.

MARCHETTI, Lorena; CULLEN, Peter. A multimodal approach in the classroom for creative learning and teaching. Psychological and creative approaches, v.5, n.1, p. 39-51, 2016.

McCLAIN, Jordan M. A framework for using popular music videos to teach media literacy. Dialogue: The interdisciplinary Journal of Popular Culture and Pedagogy, v.3, n.1, p.38-46, 2016. Disponível em:<

http://journaldialogue.org/issues/a-framework-for-using-popular-music-videos-to-teach-media-literacy/> acesso em 03 out. 2019.

NEW LONDON GROUP. A pedagogy of multiliteracies: Designing social futures. Harvard Educational Review; 66, 1, Spring, 1996.

NICOLESCU, Barasab. Um novo tipo de conhecimento: transdisciplinaridade. In: NICOLESCU, B. et al (org.). Educação e transdisciplinaridade. Brasília: UNESCO, 2000. p. 13-29.

ROJO, Roxane; MOURA, Eduardo (orgs.). Multiletramentos na escola. São Paulo: Parábola, 2012.

SERAFINI, Frank. Reading multimodal texts: perceptual, structural and ideological perspectives. Children's Literature in Education, v. 42, 2010, p. 85-104.

SERAFINI, Frank. Expanding perspectives for comprehending visual images in multimodal texts. Journal Adolescent and Adult Literacy, v. 54, n.5, p. 342-350, 2011.

STREET, Brian V. Eventos de letramento e práticas de letramento: teoria e prática nos novos estudos do letramento. In: MAGALHÃES, I. (org.). Discursos e práticas de letramento. Campinas, SP: Mercado de Letras, 2012. p. 69-92.

WARNER, Chantelle; DUPUY, Beatrice. Moving toward multiliteracies in foreign language teaching: past and present perspectives... and beyond. Foreign Language Annals, v. 51, 2017, p. 116-128. Disponível em:< https://onlinelibrary.wiley.com/doi/full/10.1111/flan.12316> acesso em 15 nov. 2019. 